\title{
REFLEXÕES SOBRE CONCEPÇÕES DE FAMÍLIA E EMPRESAS FAMILIARES
}

Hilka Vier Machado*

\begin{abstract}
RESUMO. O objetivo deste artigo é desenvolver uma reflexão sobre o conceito de empresa familiar, a partir da compreensão de transformações na estrutura da família contemporânea. A maioria dos estudos sobre empresas familiares foi desenvolvida considerando a família patriarcal como panorama de investigação. Sendo assim, a descrição sobre a atuação dessas empresas segue a mesma distribuição de poder e status da família patriarcal. Contudo, transformações culturais, econômicas e sociais têm conduzido a uma nova demografia, assim como a diferentes arranjos familiares, os quais provavelmente afetam as empresas familiares. Este ensaio teórico aborda algumas dessas transformações, apontando as relações entre elas e a concepção de empresas familiares. A análise foi estruturada a partir das seguintes categorias: o tamanho da família, a distância entre gerações e a composição e distribuição de poder. Por fim, enfatiza-se a necessidade de redimensionar a percepção de organizações familiares, abrangendo as possibilidades de diferentes arranjos familiares.
\end{abstract}

Palavras-chave: família, empresas familiares, transformações sociais.

\section{CONSIDERATIONS ABOUT FAMILY CONCEPT AND FAMILY BUSINESS}

\begin{abstract}
The aim of this paper is to present considerations about the concept of family business, considering recent transformations in the structure of contemporary family. Most of the studies about family business were developed considering the patriarchal family as the panorama of investigation. Thus, the description on the performance of these enterprises follows the same distribution of power and status of the patriarchal family. However, cultural, economical and social transformations have led to a new demography, as well as to different family arrangements, which probably have affected the family enterprises. This theoretical essay approaches some of these transformations, pointing out the relationship between these transformations and the conception of family business. The analysis was structured based on the size of the family, the distance among generations and the power composition and distribution. Concluding, it emphasizes the necessity to give new dimension to the perception of family enterprise, including different contemporary family arrange.
\end{abstract}

Key words: family, family business, social transformations.

As organizações estão inseridas na dinâmica social, política e econômica que se desenvolve no ambiente onde atuam e, simultaneamente, exercem impacto e precisam se adequar às mudanças. Sendo assim, para estudá-las é preciso considerar a realidade na qual elas se inserem, pois elas são produzidas em um dado contexto. Da mesma forma, a empresa familiar é um tipo de organização sujeito às modificações do ambiente (Lodi, 1999).

Nessa perspectiva, ao pensar a empresa familiar torna-se imprescindível compreender a noção da família no mundo contemporâneo, pois é a partir dos arranjos familiares existentes que pode emergir a noção de organizações familiares. Este tipo de organização mantém uma interação com a família, conforme salientam Chua, Christman e Steier (2003, p. 331): "Para uma empresa se sustentar como familiar no mercado competitivo do século XXI, deve haver uma sinergia e um relacionamento estreito entre a família e a empresa. A empresa precisa ter um desempenho de forma que crie valor para a família e a família precisa criar valor para a empresa. A atuação se torna impossível sem o envolvimento familiar".

A atual estrutura social, do ponto de vista das configurações familiares, apresenta-se de forma mais complexa do que duas décadas atrás, quando a noção de família patriarcal equivalia à estrutura desse núcleo de socialização. As transformações ocorridas na família ocidental contemporânea, com o crescente declínio da família patriarcal (Castells, 1999), causam impactos em empresas familiares. Sendo assim, na sociedade de hoje, é possível existir uma empresa familiar constituída por uma

* Doutora em Engenharia de Produção, docente do Departamento de Administração da Universidade Estadual de Maringá, pesquisadora do CNPq. 
família monoparental, na qual trabalham, por exemplo, mãe e filha. Apesar disso, um número considerável de estudos continua sendo desenvolvido, com o enfoque de empresa familiar e família patriarcal. É importante salientar que esse tipo de estrutura familiar não deixou de existir, mas não corresponde mais integralmente à representação de organização familiar. Nesse sentido, o aumento da complexidade se dá não somente pela dificuldade em compreender os novos arranjos familiares, mas também porque coexistem diferentes tipos de estruturas familiares dentro de uma mesma cultura.

Embora alguns estudos já considerem as transformações familiares e indiquem uma compreensão diferente do que a relacionada à família patriarcal (Campbell, 2002; Danes \& Olson, 2003; Gilding, 2000; Galbraith, 2003), é necessária ainda uma discussão acerca das transformações na família e a noção de empresa familiar, a fim de apresentar maior conformidade com a realidade social.

Assim, a premissa que orientou este ensaio teórico é a de que há um descompasso entre as concepções de empresa familiar, expressas em publicações derivadas de pesquisas com esse tipo de empresas, e as concepções vigentes de família ou de arranjos familiares. Sendo assim, o objetivo desse artigo é desenvolver uma reflexão sobre o conceito de empresa familiar a partir da compreensão de transformações na estrutura da família contemporânea.

A fim de atingir o objetivo proposto, desenvolveu-se um ensaio teórico, oriundo de uma pesquisa temática envolvendo as variáveis: família e empresas familiares. Utilizando-se fontes secundárias de dados, sobretudo nas áreas de Antropologia, Psicologia, Sociologia e Administração, discute-se a concepção de empresa familiar à luz de dimensões da família contemporânea. Procurou-se identificar transformações familiares apontadas na literatura e verificar se elas estavam inseridas na concepção de empresa familiar que embasa pesquisas sobre o assunto. Identificaram-se três categorias abrangentes, constitutivas de aspectos fundamentais que necessitam ser incorporados e considerados nos estudos sobre empresas familiares: o tamanho da família, a distância entre gerações e a composição e distribuição de poder.

A estrutura do trabalho inicia-se com algumas considerações sobre transformações na família contemporânea, e em seguida discute-se o impacto dessas mudanças na concepção de empresas familiares.

\section{A FAMÍLIA E TRANSFORMAÇÕES RECENTES}

Na concepção tradicional, a família é constituída de um grupo de pais e filhos, ou, em um sentido mais abrangente, incluindo também parentes próximos. Esse conceito corresponde à noção de família nuclear ou família extensiva, mas a compreensão da família altera-se principalmente na década de 1990. Desta forma, enquanto na concepção de Todd (1985) o conceito de família está inserido em um sistema ideológico mais amplo, ao mesmo tempo que desenvolve e reproduz um sistema de valores próprios, Belardinelli (2002) ressalta que na sociedade contemporânea religião, política, leis, moralidade e família tornam-se sistemas separados.

Segundo Castells (1999, p. 169), a principal transformação que está ocorrendo na família é o fim do patriarcalismo, que "caracteriza-se pela autoridade, imposta institucionalmente, do homem sobre mulher e filhos no âmbito familiar". Este sistema, segundo o autor, está enraizado na civilização, em razão da sua perpetuação histórica e cultural, determinando também relacionamentos interpessoais que extrapolam os limites da família. Um dos principais fatores, na perspectiva de Castells (1999), que determinou essa mudança é a inserção das mulheres no mercado de trabalho. A partir da década de 1980, concomitantemente com a globalização, foi generalizada a ampliação de mulheres em postos de trabalhos. Outro fator relaciona-se às transformações tecnológicas, proporcionando controles sobre a reprodução humana. Em terceiro lugar, para o autor, está o movimento feminista, com impacto na esfera do trabalho e na eliminação de qualquer forma de opressão ou desigualdade de poder. Além desses fatores, o autor menciona a difusão de uma idéia de cultura globalizada, na qual está inserida a noção de uma nova identidade feminina, decorrente da emancipação feminina.

Esse contexto de transformações é acompanhado de novas formas de pensar a vida familiar, incluindo "inclusive as famílias gays" (Castells, 1999, p. 172). Esse movimento dá origem a uma crise da família patriarcal, representada pelo "enfraquecimento do modelo familiar baseado na autoridade/dominação contínua exercida pelo homem, como cabeça do casal, sobre toda a família" (Castells, 1999, p. 173). Uma vez que, cada vez mais, a dissolução dos casamentos leva à formação de lares de solteiros ou lares com apenas um dos pais, cessa a autoridade patriarcal sobre a família. Também Gomes e Paiva (2003), discorrendo sobre o casamento e família no século XXI, referemse a uma nova configuração do conceito de casamento, uma vez que "as famílias vão se constituindo de forma mais ampla, incluindo os novos parceiros (marido da mãe/esposa do pai) e os filhos e irmãos agregados, sendo que o pai perde substancialmente a tradicional figura e função, já que um grande número de famílias é constituído apenas pela figura materna" (p.5). Dias e 
Lopes (2003) consideram que a família surgida nos anos 80 é mais igualitária, sendo os seus membros percebidos como iguais, com direitos similares, embora diferenças sexuais e etárias se encontrem presentes. Nesse contexto novos papéis se inserem no cenário familiar, como, por exemplo, o de pai ou mãe substituta (Fonseca, 2002).

Castells (1999) salienta ainda que o adiamento da formação de casais, derivado da dificuldade de compatibilizar casamento, trabalho e vida e a formação de relacionamentos sem casamento legalizado, contribui para enfraquecer a autoridade patriarcal, tanto institucional como psicologicamente. Para ele, "essas tendências indicam o fim da família como a conhecemos até agora: não apenas a família nuclear, mas a baseada no domínio patriarcal, que tem predominado há milênios" (Castells, 1999, p. 174).

Segundo Fonseca (2002), não há um modelo homogêneo e hegemônico quando se busca compreender as formas familiares predominantes na sociedade atual. De acordo com a autora, o modelo atual é uma extensão do ideal de família preconizado na modernidade, que enfatiza o amor romântico, o matrimônio ideal e o afeto como base da vida familiar. $\mathrm{Na}$ medida em que esses valores foram se incorporando à vida conjugal, as relações tornaram-se abertas à negociação, permitindo a legitimação de formas familiares outrora não aceitas socialmente como, por exemplo, a de parceiros do mesmo sexo - as quais ganharam um espaço importante nesse novo contexto, em que a afeição é a verdadeira base do relacionamento. Outro aspecto comentado pela autora é o aumento do número de crianças nascidas fora do casamento, aspecto que estabeleceu uma desconexão entre elementos que historicamente eram interligados: casal, casamento e família. Ela acrescenta ainda que, se antes a tradição era transmitida sob a forma de valores familiares, de uma geração para outra, caracterizando a importância do passado e a concepção de indissolubilidade da família, com ênfase na consangüinidade, nas relações sociais contemporâneas a ênfase está no presente, no bemestar do momento, não importando a indissolubilidade ou o passado.

Além da ênfase no presente, Belardinelli (2002) comenta que o aumento do individualismo nas relações familiares contemporâneas muitas vezes contribui para uma diminuição da confiança entre seus membros. Para ele, o individualismo corresponde a uma autonomia individual, presente na sociedade de hoje, que valoriza homens mais independentes e livres, criadores de si mesmos. Com esse modo de agir a família passa a ser um mero espaço de comunicação, sendo que a informação é mais valorizada do que a formação.
Essas alterações nas estruturas familiares revelam que o que está em jogo "não é o desaparecimento da família, mas sua profunda diversificação e a mudança do seu sistema de poder", tendo em vista que a família patriarcal representa uma minoria no contexto social de diversas localidades (Castells, 1999).

À guisa de conclusão, percebe-se que a noção de família envolve atualmente uma complexidade, na medida em que diferentes formas coexistem na mesma cultura, representando uma composição diferenciada da família nuclear tradicional e patriarcal, tanto pelos seus integrantes e pela redefinição de papéis familiares como pela nova distribuição de poder. Sendo assim, de modo sucinto, pode-se observar que a dinâmica familiar adquire novos contornos, principalmente no que se refere a alguns aspectos:

- distribuição de poder: como já discutido anteriormente, estudiosos apontam como um dos principais aspectos da transformação familiar a nova distribuição de poder, resultante da queda da estrutura patriarcal.

- distância entre gerações: outro aspecto diferenciado nos arranjos familiares atuais é representado pelo aumento da distância de idade entre gerações, gerado pelo fato de os indivíduos terem filhos com idade mais avançada do que em gerações anteriores. Apesar disso, o convívio entre gerações se apresenta modificado, principalmente com a intensificação da convivência entre avós e netos, muitas vezes maior do que entre pais e filhos.

- tamanho da família: uma das transformações na família contemporânea é o tamanho das famílias, reduzido em função do menor número de filhos. Fatores como o ingresso de mulheres no mercado de trabalho, a redução de níveis de renda ou até mesmo o predomínio do individualismo podem ter contribuído para a redução no tamanho da família. Além disso, outros fatores, como a necessidade de formação contínua da mão-de-obra economicamente ativa, derivada do aumento da complexidade do trabalho, dificultam a conciliação entre trabalho e família e em consequiência se constituem em fatores limitantes do número de filhos. Entretanto, convém mencionar que, no caso de casamentos sucessivos, ocorre muitas vezes uma ampliação da família, envolvendo filhos de casamentos diferentes.

A partir dessa síntese de transformações da família buscou-se compreender as suas implicações nas empresas familiares, apresentadas a seguir. 


\section{FAMÍLIA E EMPRESA FAMILIAR NO CONTEXTO CONTEMPORÂNEO}

Verstraete (2000) chama a atenção para a dificuldade em definir empresa familiar. Numa perspectiva tradicional, a empresa familiar é considerada assim se o controle da propriedade está nas mãos de um indivíduo ou dos membros de uma mesma família. Juntamente com esses fatores, a gestão da empresa e a vontade do proprietário de transmitir a empresa para a próxima geração também podem configurar uma empresa como familiar. Para Leone (1992), a empresa é familiar quando foi iniciada por um membro da família, quando membros da família participam da propriedade ou direção, ou ainda quando há valores institucionais ligados à família e a sucessão está vinculada à família. Em geral, os estudos sobre empresas familiares (Westhead \& Cowling, 1998) consideram que a propriedade, a gestão e a sucessão ou a intenção de passar o bastão definem uma empresa como familiar.

Ao considerar a empresa familiar como a que tem a família no controle e gestão da propriedade, essa compreensão só se torna possível a partir do momento em que se define claramente quem é a família. Para o estudo de empresas familiares essa clareza é uma questão epistemológica que não pode ser negligenciada, pois os principais obstáculos para a definição de empresa familiar estão relacionados com as diferentes concepções culturais de família, como salienta Stewart (2003) e com a dificuldade em definir o que é família (Dyer, 2003). Dyer ressalta que atualmente o número de empresas iniciadas e dirigidas por casais é cada vez maior, e tanto situações de consangüinidade quanto de matrimônio podem ser consideradas para fins de empresas familiares.

Nessa perspectiva, Allouche e Amann (1999), ao discorrerem sobre o conceito de empresa familiar, fazem questionamentos sobre a compreensão de tal tipo de empresa. Segundo eles, a empresa pode ser considerada familiar quando:

- o envolvimento ocorre com uma família nuclear ou um conceito de família extensiva;

- há laços consanguíneos entre os proprietários da empresa ou eles são casados.

Do mesmo modo, essa dificuldade é mencionada por Chua e Christman (1999), ao encontrarem como proprietários desse tipo de empresas situações diversificadas, tais como:

- um indivíduo;

- duas pessoas ligadas por laços consangüíneos;

- duas pessoas ligadas pelo casamento;
- família nuclear;

- mais do que uma família nuclear;

- família extensiva.

Essa realidade apresentada pelos autores indica o impacto exercido pelas transformações familiares na compreensão de empresa familiar, pois tradicionalmente a família nuclear era a que predominava e, na maioria das vezes, era o patriarca da família que representava o papel de sucessor.

Além da importância do conceito de família para a empresa familiar, as transformações recentes na família, discutidas anteriormente, também interferem nas empresas familiares e são discutidas a seguir.

\section{Tamanho da família}

Do ponto de vista da empresa familiar verifica-se, obviamente, que o número de potenciais sucessores foi também reduzido. Segundo Malinen (2001), quanto maior o tamanho da família, maior número de potenciais sucessores haverá. Atualmente, não são raros os casos de empresas familiares que possuem apenas um sucessor e em que as empresas são vendidas porque o sucessor não tem intenção de prosseguir com o empreendimento.

Por outro lado, se a família extensiva é a resultante de casamentos sucessivos, não são poucos os casos em que a empresa familiar é o local de trabalho para os filhos do primeiro casamento, assim como os do segundo e os agregados, ampliando sobremaneira o envolvimento familiar na empresa.

Um outro ângulo de estudos é apresentado por Galbraith (2003), que, ao investigar o relacionamento entre divórcio e desempenho financeiro, identificou o que chamou de "esposa in" e "esposa out", para caracterizar a esposa atual e a anterior, demonstrando que os laços de lealdade entre empregados se estabeleciam de forma fracionada entre as duas integrantes da família (anterior e atual).

A ambigüidade dessas situações ilustra o aumento da complexidade da empresa familiar, pois a família foi reduzida em muitos casos, mas ao mesmo tempo ampliada em outros casos, sendo que essa transformação impacta diretamente os processos sucessórios, de distribuição de poder e de comunicação.

\section{Distância entre gerações}

Quando se analisa o impacto dessa transformação demográfica na empresa familiar, verifica-se, por exemplo, que os filhos nascidos quando seus pais tinham 30 anos ou mais vão ao mercado de trabalho quando os 
pais estão próximos dos 60 anos, ou seja, próximos da aposentadoria. O convívio entre sucessor e sucedido na empresa passa a ser mais curto e a distância de idade é maior, o que pode interferir no processo de transição e continuidade dessas organizações, pois o gerenciamento pelos sucessores pode ser muito diferente daquele adotado pelo sucedido.

\section{Composição da família e distribuição de poder}

As mudanças ocorridas nas características familiares das sociedades ocidentais contemporâneas, tais como a autonomia individual e a igualdade entre gêneros, afetam as organizações familiares (Gilding, 2000). Apesar disso, o foco de muitos estudos familiares é ainda predominantemente centrado no empreendedor como a figura paterna, ainda que as alterações na família indiquem a necessidade de incluir a perspectiva de gênero na pauta desses estudos (Goffee, 1996; Sharma, Chrisman \& Chua, 1996). Mesmo que pesquisas - como a de Rowe e Hong (2000) - destaquem a influência das esposas na direção de empresas familiares, o papel dessas mulheres não representa um poder legítimo nas organizações.

Estudos recentes indicam que há resistências em empresas familiares em aceitar mulheres na sucessão (Stavrou, 1999; Vidigal, 2000) e que estas são consideradas possíveis sucessoras somente quando não há sucessores do sexo masculino, sendo que a atuação de mulheres em empresas familiares às vezes só é permitida de forma invisível (Curimbaba, 2002; Rowe \& Hong, 2000). Restrições de ordem cultural limitam o ingresso de mulheres na sucessão de empresas familiares, como Vidigal (2000, p. 68) encontrou entre as empresas familiares de brasileiros de origem italiana, entre os quais há o "hábito de não permitir que as filhas se tornem sócias da empresa”.

Rodrigues (1991) salienta que a empresa familiar, na maior parte das vezes ainda é um "negócio entre homens". Deste modo, há um descompasso entre a realidade social e a representação social de sucessores, que está em geral associada à figura masculina. Por exemplo, em um estudo desenvolvido junto a 549 famílias canadenses, Gasse (citado por Very \& Raytcheva, 2002) constatou que $39,7 \%$ das pessoas envolvidas nessas empresas julgavam que os filhos eram as pessoas mais competentes para assumir as empresas, sendo que apenas $9,6 \%$ apontaram as filhas. Antes delas estavam os sócios $(20,6 \%)$ e até mesmo as pessoas que não faziam parte da empresa (16,9\%). Além disso, como os estudos sobre as empresas familiares estão, na maioria, pautados sobre organizações criadas e dirigidas por homens (Handler citado por Cadieux, Lorrain \& Hugron, 2000), são escassas as contribuições acerca do processo sucessório em empresas criadas e geridas por mulheres (Cadieux, Lorrain \& Hugron, 2000).

$\mathrm{O}$ preparo de sucessores, que em geral era centrado na relação de pais e filhos, hoje tem como possibilidades múltiplas relações, envolvendo: mãe e filha(s); mãe e filho(s); pai e filho(s); pai e filha(s). Considerando as diferentes naturezas desses relacionamentos, essas possibilidades devem ser incluídas nas pesquisas, a fim de melhor se compreenderem as empresas familiares contemporâneas (Goffee, 1996). Também Dyer (2003) ressalta a importância de estudos que caracterizem relacionamentos familiares do tipo: paifilho, pai-filha, mãe-filho, mãe-filha, tio-sobrinho, e assim por diante. $\mathrm{O}$ autor salienta ainda a importância de desenvolver estudos sobre grupos familiares, pois para ele, um grupo constituído pelo pai e seus quatro filhos seria diferente de um grupo de quatro filhas que estivessem gerenciando uma empresa em conjunto.

Nessa perspectiva, estudos qualitativos podem fornecer elementos que facilitem a compreensão da nova realidade social nessas empresas. Essa visão do fenômeno contribui para que o conceito de empresa familiar seja mais adaptado à dinâmica familiar contemporânea e à distribuição de poder vigente no grupo. Um exemplo é o estudo realizado por Campbell (2002), em empresas em que atuam mães e filhas. Ela destacou como pontos positivos na preparação das sucessoras os seguintes:

- facilidade de aprendizado, tendo a mãe como mentora;

- o respeito ao papel da mãe, pois ela representa fonte de força e sabedoria;

- $\quad$ interdependência e suporte mútuo;

- a filha sente-se como uma aliada e não como uma subordinada.

Esses resultados encontrados por Campbell (2002) contribuem para reforçar as recomendações de Dyer (2003), na medida em que apontam resultados que não coincidem com os de estudos realizados entre pais e filhos sucessores, onde o conflito é comumente encontrado (Malinen, 2001).

Por meio desses exemplos pode-se perceber que há uma nova dimensão de empresa familiar, resultante dos múltiplos arranjos familiares possíveis. Essa realidade indica a necessidade de reformular conceitos e premissas que até então orientavam o estudo de organizações familiares.

Por fim, se anteriormente existia dificuldade em compreender o conceito de família, pois esse variava de 
acordo com a cultura, o desafio do momento se apresenta dentro da mesma cultura, onde coexistem diferentes arranjos familiares. Talvez, do ponto de vista de empresas familiares, seja preciso estabelecer uma demografia dessas empresas, que englobe, por exemplo, casais empreendedores, mulheres e homens empreendedores com suas respectivas famílias nucleares ou extensivas.

\section{CONSIDERAÇÕES FINAIS}

Quando se utiliza a metáfora da família em uma empresa, a noção de família parece clara entre seus integrantes; por outro lado, paradoxalmente, esta noção para a empresa familiar apresenta-se de forma complexa, conforme discutido neste estudo.

Assim, ao abordar as transformações na estrutura familiar, verifica-se que uma nova dimensão de família se apresenta, principalmente no Mundo Ocidental. Transpondo-se a reflexão para o campo das empresas familiares, não resta dúvida quanto à necessidade de um enfoque ampliado do fenômeno, que considere as novas possibilidades de arranjos familiares, já existentes em organizações. Essa discussão é necessária, pois as representações sociais sobre família, no ambiente de negócios, principalmente para a empresa familiar, estão ainda muito relacionadas à lógica da família patriarcal, sendo que esta representa atualmente uma pequena parte das estruturas familiares. Sendo assim, é necessário que pesquisas adicionais sejam realizadas, enfocando as transformações familiares e os novos arranjos organizacionais familiares delas decorrentes.

Embora alguns dos estudos mencionados apontem na direção de uma flexibilização no conceito de empresa familiar, como, por exemplo, a aceitação de casamento ou da consangüinidade, apontada por Dyer (2003), há outros aspectos importantes, como a noção de que não é preciso existir casal para existir família. Somente a partir de enfoques dessa natureza é que se pode romper o ciclo vicioso que associa empresa familiar e família patriarcal, na medida em que essa representação não corresponde integralmente ao retrato de família.

Por fim, estudos longitudinais em empresas familiares poderiam contribuir para esclarecer melhor o impacto de transformações na família e na empresa, principalmente do ponto de vista da composição e da distribuição do poder.

\section{REFERÊNCIAS}

Allouche, J. \& Amann, B (1999). L'entreprise familiale: un état de l'art. Finance, Contrôle, Stratégie, 1-34.
Belardinelli, S. (2002). The evolution of family institution and its impact on society and business. Family Business Review, $X V(3), 169-173$.

Cadieux, L. Lorrain, J. \& Hugron, P. (2000). La succession dans les entreprises familiales: une étude de cas exploratoire faite auprès de quatre PME manufacturieères fondées et dirigées par des femmes. Actes $V$ Congrès International Francophone sur la PME, Lille: CIFPME.

Campbell, K. L. (2002). Theorizing Matrilineal Business Enterprises to Add Mother/Daughter Business to the Entrepreneurial Mix. Proceedings ICSB 47th World Conference, Puerto Rico: ICSB.

Castells, M (1999). O poder da identidade. São Paulo: Paz e Terra.

Chua, J. H. \& Christman, J. J. (1999). Defining the family business by behaviour. Entrepreneurship Theory and Practice, 23(4), 19-38.

Chua, J., Chrisman, J. \& Steier, L. (2003). Extending the Theoretical Horizons of Family Business Research. Entrepreneurship Theory and Practice, Summer, (pp.331-338).

Curimbaba, F. (2002). The dynamics of women's roles as family business managers. Family Business Review, 15(3), 239246.

Danes, S. \& Olson, P. (2003). Women's role involvement in family businesses, business tensions, and business success. Family Business Review, 16(1), 53-68.

Dias, A. C. \& Lopes, R. C. (2003). Representações de maternidade de mães jovens e suas mães. Psicologia em Estudo, 8 (especial), 63-73.

Dyer, W.G (2003). The family: the missing variable in organizational research. Entrepreneurship Theory and Practice, 27(4), 401-416.

Fonseca, C. (2002, abril). Olhares antropológicos sobre a família contemporânea, Comunicação apresentada no Congresso Internacional Pesquisando a família. Florianópolis.

Galbraith, C. S. (2003). Divorce and the financial performance of small family businesses: an exploratory study. Journal of Small Business Management, 41(3), 296-309.

Gilding, M. (2000). Family business and family change: individual autonomy, democratization, and the new family business institutions. Family Business Review, 12(3), 239-249.

Goffee, R. (1996). Understanding family businesses: issues for further research. International Journal of Entrepreneurial Behavior \& Research. 2(1), 36-48.

Gomes, I. C. \& Paiva, M. L. (2003). Casamento e família no século XXI: possibilidade de holding? Psicologia em Estudo, 8 (especial), 3-9.

Leone, N. (1992). A sucessão em PME comercial na região de João Pessoa. Revista de Administração, 27(3), 84-91.

Lodi, J. B. (1999). Fusões e aquisições: o cenário brasileiro. Rio de Janeiro: Campus.

Malinen, P. (2001). Like father like son? Small family business succession problems in Finland. Enterprise and Innovation Management Studies, 2 (3), 195-204.

Rodrigues, A. M. (1991). Padrões afetivos na família e empresa familiar. Revista de Administração de Empresas, 31(4), 35-48. 
Rowe, B. \& Hong, G. (2000). The role of wives in family businesses: the paid and unpaid work of women. Family Business Review, 13(1), 1-13.

Sharma, P., Chrisman, \& J., Chua, J. (1996). A review and annotated bibliography of family business studies. London: Klewer Academic Publishers.

Stavrou, W (1999). Succession in family businesses: exploring the effects of demographic factors on offspring intentions to join and take over the business. Journal of Small Business Management, 37(3), 43-61.

Stewart, A. (2003). Help one another, use one another: toward anthropology of family business. Entrepreneurship Theory and Practice, 27(4), 383-396.

Todd, E (1985). The explanation of ideology: Family structures and social systems. Oxford: Blackwell.
Verstraete, T. (2000). Histoire d'entreprendre. Paris: Éditions Management \& Societé.

Very, P. \& Raytcheva, S. (2002, April). Family structures, family firms and succession: some insights from Anthropology. Proceedings, $47^{\text {th }}$ World Conference, Puerto Rico: ICSB.

Vidigal, A. C. (2000). A sobrevivência da empresa familiar no Brasil. Revista de Administração, 35(2), 66-71.

Westhead, P. \& Cowling, M. (1998). Family firm research: The need for a methodological rethink. Entrepreneurship Theory and Practice, 23(1), 31-56.

Recebido em 25/05/2004

Aceito em 30/01/2005

Endereço para correspondência: Hilka Vier Machado, Rua Saint Hilaire, 2055, 87015-161, Maringá-PR.

E-mail: hilkavier@yahoo.com 